\title{
Experimental Study on Wear Characteristics of PCBN Tool with Variable Chamfered Edge
}

\author{
Tao Chen*, Lixing Song, Suyan Li and Xianli Liu
}

\begin{abstract}
Owing to heavy dynamic and thermal loads, PCBN tools are seriously worn during hard cutting, which largely constrains the improvement of their machining performance. Therein, the chamfered structure of a cutting edge has a notable influence on the tool wear. Thus, a comparative study was carried out on the wear morphology and wear mechanism of PCBN tools with either a variable chamfered edge or an invariable chamfered edge. The results indicate that, for a PCBN tool with a variable chamfered edge, the rake wear area is far from the cutting edge and slowly extends toward it. A shallow large-area crater wear occurs on the rake face, and the flank wear area has a long triangular shape with a smaller wear area and width, and the cutting edge remains in a good state during the cutting process. In contrast, for a PCBN tool with an invariable chamfered edge, a deep small-area crater appears on the rake face, and the wear area is close to the cutting edge and quickly extends toward it. Thus, it is easy for chips to accumulate in the crater, resulting in large-area and high-speed wear on the flank face. In addition, the tool shows a weak wear resistance. In the initial wear stage, the rake wear mechanism of the two cutting tools is a mixture of abrasive, oxidation, and other types of wear, whereas their flank wear mechanism is dominated by abrasive wear. With an aggravation of the tool wear, the oxidation and diffusion wear mechanism are both increasingly strengthened. The rake wear of the cutter with a variable chamfered edge showed an obvious increase in the oxidation and diffusion wear, as did the flank wear of the cutter with an invariable chamfered edge. This study revealed the wear mechanism of the PCBN tool with a variable chamfered edge and provided theoretical and technological support for its popularization and application in the machining of high-hardness materials.
\end{abstract}

Keywords: Hard cutting, Variable chamfered edge, PCBN tool, Wear morphology, Wear mechanism

\section{Introduction}

Characterized by a high hardness, strength, and fragility, but a poor thermal conductivity, hardened steel is typically regarded as a difficult-to-machine material [1], and its finish cutting is usually conducted using PCBN tools. During the machining hardening of steel, heavier mechanical and thermal loads occur in the cutting area $[2,3]$, and thus at high temperature and high pressure, the tool-workpiece and tool-chip friction become severe, resulting in quick rake and flank wear. In particular, when the tool wear develops beyond a certain extent, the cutting force and cutting temperature clearly increase and vibrations will even occur [4-7], which will cause further

\footnotetext{
${ }^{*}$ Correspondence: chentao@hrbust.edu.cn

School of Mechanical and Power Engineering, Harbin University

of Science and Technology, Harbin 150080, China
}

breakdowns such as chipping, fragmenting, rupturing, and peeling. This has a serious impact on the machining surface quality, and improvements of the hard machining performance plateau.

Scholars both at home and abroad have carried out numerous related studies on PCBN tool wear. Chou et al. [8] researched the effects of the CBN content on the tool wear during hard machining, and concluded that a tool with a low $C B N$ content has a relatively smaller wear rate than a tool with a high CBN content, and its machining surface quality is more satisfactory. Zhou et al. [9] conducted an experimental study on the machining of hardened steel $100 \mathrm{Cr} 6$ using a PCBN tool, and determined the effects of the chamfer angles on the tool wear. Based on an experiment on the cutting of hardened steel AISI4340, Coelho et al. [10] studied the influence of the coating types on the PCBN tool wear, and found that 
a TiAlN nano coating cutting tool is the least worn, a tool coated with TiAlN is less worn, a tool coated with $\mathrm{AlCrN}$ is more worn, and an uncoated tool is the most worn. Arsecularatne et al. [11] studied the effects of the cutting parameters on the tool wear in the machining of hardened steel AISI D2 using a PCBN tool, and proposed optimum cutting parameters aiming at the tool life and volume of the material removal. Poulachon et al. [12] investigated the influence laws of the PCBN tool wear morphology, based on different hardened steels, and revealed that the tool flank grooves have a correlation with the microstructure of these steels. Zhao et al. [13] focused on the surface roughness evaluation during hard turning and found that the cutting-edge radius of the PCBN tool has a significant influence on the surface roughness and tool wear. Das et al. [14] carried out an experiment on the hard turning of AISI 4140 steel using ceramic tools coated with PVD-TiN and revealed that the surface roughness is mainly influenced by the feed and cutting speed. Anmark et al. [15] researched the fine machining of carburizing steel using PCBN tools, and determined the correlation between the tool wear mechanism and the inclusion components in the workpiece materials. Ramanuj et al. [16] compared the wear characteristics in the hard turning of AISI D2 steel using a coated carbide cutter and a ceramic cutter individually, and found that the wear mechanisms of the coated carbide tool are mainly abrasion, diffusion, and notching wear, whereas the ceramic tool showed a good stability without a catastrophic failure. Mahfoudi et al. [17] investigated the tool wear that occurs when the PCBN tool is used to machine harden steel AISI 52100 at a high speed, and established a crater wear prediction model based on the temperature distribution in the tool-chip contact area. In addition, Huang et al. [18] built a model for predicting the rake crater wear depth of a PCBN tool, and verified its accuracy experimentally, during which the PCBN tool was used to cut hardened steel AISI 52100. Combining FEA with the cutting experiments, Özel et al. $[19,20]$ conducted comparative research into the wear morphology and wear process of two different PCBN tools with a variable rounded edge and an invariable chamfered edge. In addition, other researchers have focused on the tool wear mechanisms, such as abrasive wear, bond wear, diffusion wear, and chemical wear, during hard turning [21-24].

In conclusion, the current study on tool wear during hard turning focuses on PCBN tools with an invariable chamfered edge. In comparison, a tool with a variable cutting edge can form a spatially curved edge and therefore improve the thermolysis of the chip removal and tool life, reducing the cutting resistance. Such merits have drawn the attention from concerned scholars, and have been preliminary explored regarding tool fabrication techniques [25-27] and the cutting performance [28-30]. A PCBN tool with a variable chamfered edge was studied, and research into its wear morphology and mechanism was carried out based on a high-speed hard turning experiment.

\section{Structural Characteristics of PCBN Tool with Variable Chamfered Edge}

A PCBN tool with a variable chamfered edge and such a tool with an invariable chamfered edge differ in their chamfered structures. The chamfered structure of the latter has a fixed width and angle, whereas that of the former consists of a fixed-parameter area and a variableparameter area. The fixed-parameter area, whose chamfer width and angle are both fixed, starts at the linear edge and extends toward the rake face, whereas the variable-parameter area begins from the curved edge, and its chamfer width is fixed, but its chamfer angle is variable, as shown in Figure 1.

To further illustrate the structural characteristics of a variable chamfered edge, five cross-sections were extracted, namely, A, B, C, D, and E. In Figure 1, the value of chamfer width $\mathrm{L}$ was fixed, and the chamfer angle $\alpha_{i}$ was variable and varied linearly along the corner radius, forming only two symmetrical reverse spiral edge lines. The chamfer width was $0.15 \mathrm{~mm}$, the minimum chamfer angle was $-15^{\circ}$, and the maximum angle was $-30^{\circ}$.

\section{Experimental Scheme}

A corresponding high-speed hard turning experiment was designed in this study to investigate the wear morphology and wear mechanism of the cutting tool with a variable chamfered edge. The experiment was conducted on a numerically controlled lathe CK6150, in which a

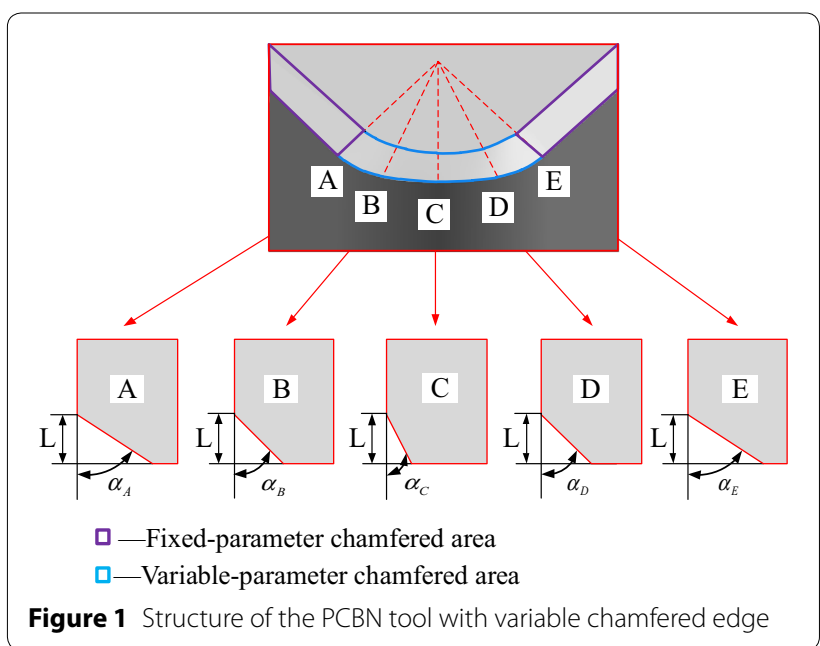


Table 1 Major chemical composition of GCr15 (mass fraction, \%)

\begin{tabular}{llllll}
\hline Element & C & Mn & Si & Cr & S \\
\hline Composition & $0.95-1.05$ & $0.20-0.40$ & $0.15-0.35$ & $1.30-1.65<0.020$ \\
\hline
\end{tabular}

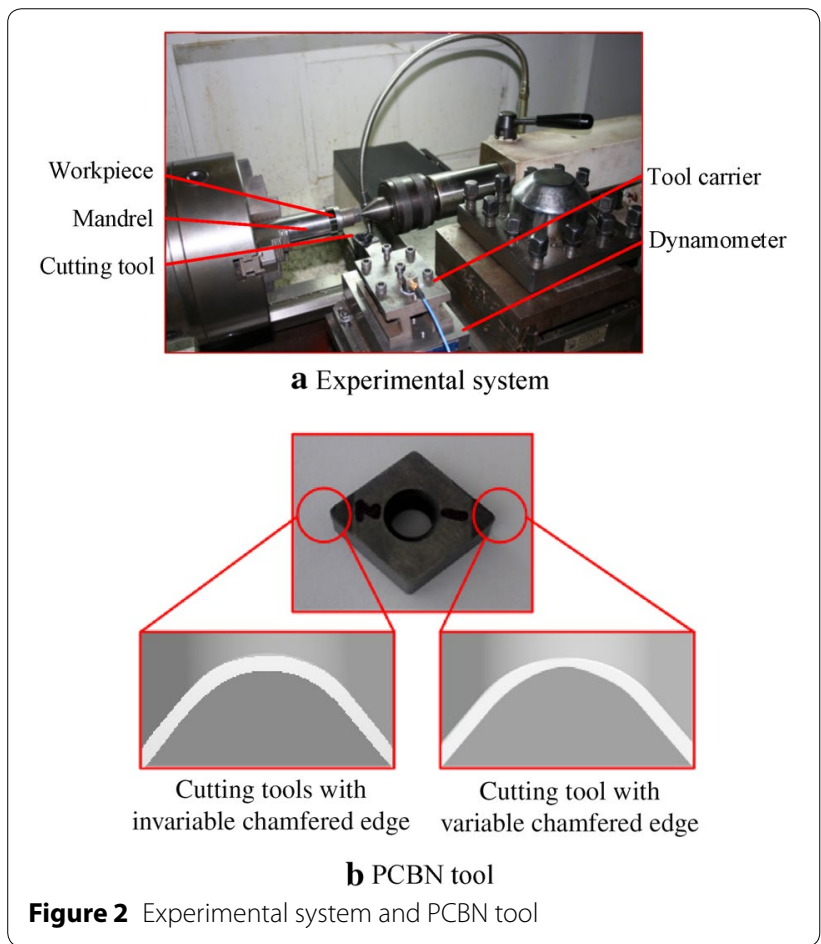

GCr15 bearing outer ring with a hardness of $60 \pm 2$ HRC served as the workpiece, and its outer diameter was $62 \mathrm{~mm}$, its width was $17 \mathrm{~mm}$, and its major chemical composition was as shown in Table 1. Self-made PCBN tools with a variable chamfered edge and an invariable chamfered edge were both used in the experiment. The two tools shared the same specifications, namely, CNGA1204. Specifically, the granularity was $1.5 \mu \mathrm{m}$, the CBN content was $50 \%$, the invariable chamfer parameter was $0.15 \mathrm{~mm} \times 30^{\circ}$, the corner radius was $0.8 \mathrm{~mm}$, the tool shank was a DCLNR 2525M12, and after the cutting tool was set, the rake angle was $-6^{\circ}$, the clearance angle was $6^{\circ}$, the cutting edge angle was $95^{\circ}$, and the minor cutting edge angle was $5^{\circ}$. The experimental system and cutting tools are as shown in Figure 2.

During the experiment, the fixed cutting parameters were as follows. The cutting speed was $150 \mathrm{~m} / \mathrm{min}$, the cutting depth was $0.1 \mathrm{~mm}$, and the feed rate was $0.2 \mathrm{~mm} / \mathrm{r}$. A PCBN tool with a variable chamfered edge and a tool with an invariable chamfered edge were successively used in the cutting experiment. For every 20 feeds, the workpiece and chips were kept for a subsequent

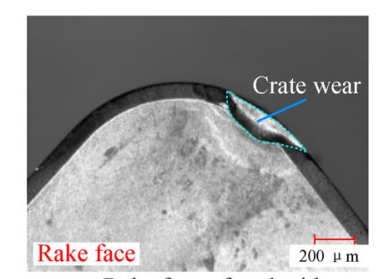

a Rake face of tool with invariable chamfered edge

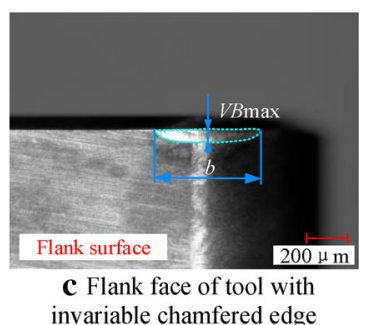

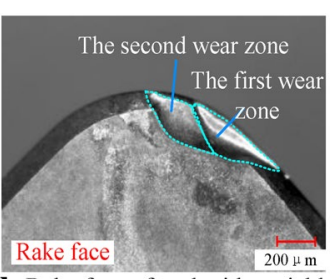

b Rake face of tool with variable chamfered edge

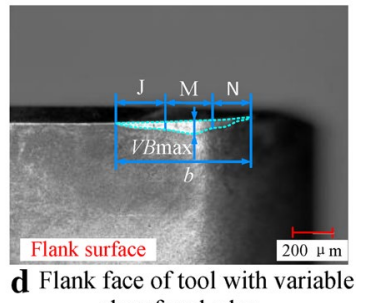
chamfered edge chamfered edges

testing of the surface quality and chip micromorphology; in addition, an extended depth field microscope (VHX1000) and an electronic scanning microscope (FEI, Sirion 200) were used to test the tool wear, and the cutting forces were measured using a piezoelectric dynamometer (Kistler, 9257B) until the blade damage ended the experiment.

\section{Experimental Results and Analysis}

\subsection{Wear Morphology of Cutting Tool}

Figure 3 shows the rake and flank wear morphology of the two PCBN tools with different chamfered edges when the flank wear reached $0.1 \mathrm{~mm}$. Figure 3(a) focuses on the tool with an invariable chamfered edge; its rake wear was crater-shaped and mainly concentrated on the chamfered surface, and the wear area was smaller. In contrast, Figure 3(b) focuses on the tool with a variable chamfered edge, in which two crater wear zones occurred on its rake face, and the wear area was clearly large, namely, beyond the chamfered surface and extended to the rake face. Figure 3(c) shows the flank wear zone of the tool with an invariable chamfered edge, which has a flat-arc, and the wear area was distributed evenly and almost indistinctively. In Figure 3(d), however, the wear zone of the tool with a variable chamfered edge was a long triangle and distributed in a relatively dispersive manner, in which the 
areas of both ends $\mathrm{J}$ and $\mathrm{N}$ were less worn, and the middle area was more worn. In addition, the wear width $b$ of the tool with a variable chamfered edge was larger than that of the tool with an invariable chamfered edge; nonetheless, the wear area size of both tools showed a small difference.

To further analyze the change law of wear morphology of the two tools above as time passed, corresponding test indicators were needed to define the geometrical characteristics of the tool wear area. The rake crater wear had a significant influence on the cutting edge strength, which was evaluated by indicators such as the wear area $S$, wear depth $K_{\mathrm{T}}$, and distance from the crater wear bottom to the cutting edge $L$. Owing to the complexity of the crater wear morphology, a white-light interferometer was used to test the relative indicators. First, the crater wear area was scanned using the white-light interferometer, as shown in Figure 4(a). The related parameters were then extracted using a hole feature instrument, as shown in Figure 4(b). That is, the surface parameters included the crater wear area $S$, the maximum depth of which was the crater wear depth $K_{\mathrm{T}}$. Finally the sectioning function of the white-light interferometer was used to extract the crater wear section $H$, as shown in Figure 4(c), and the distance from the crater wear bottom to the cutting edge $L$ can be obtained from the section contour. The flank face is a key factor influencing the machined surface

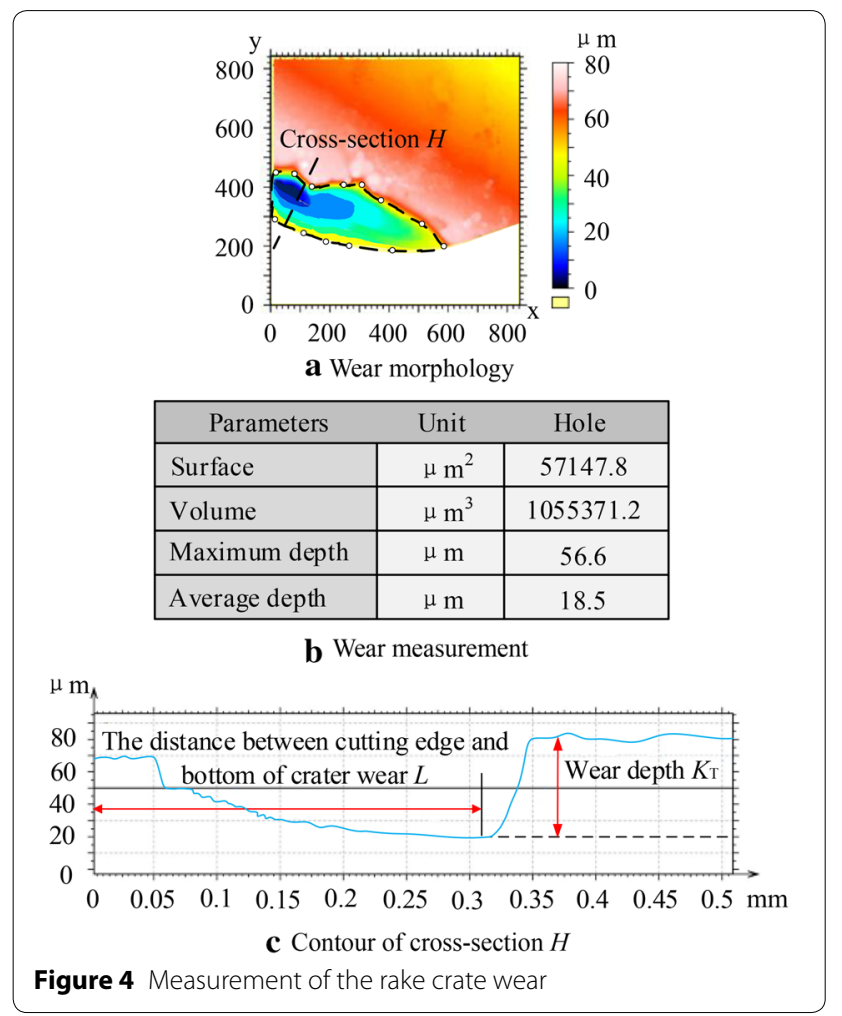

quality, and thus the maximum wear width $V B_{\max }$ and wear depth $b$ were chosen as indicators, and an extended depth of field microscope VHX-1000 was used to test them.

Figure 5 shows the change curves of the rake crater wear area and depth of the two cutting tools with different chamfered edges as the cutting time continued. It can be seen from Figure 5 that the wear curves of the two cutting tools had a minor difference during the initial $4 \mathrm{~min}$, but both the crater wear area and depth clearly increased as the cutting proceeded, and the cutting tools were quickly worn. When the cutting time passed $12 \mathrm{~min}$, the wear areas of both cutting tools slowly increased and the wear depth grew explosively; their wear morphology is approximated herein. However, when the cutting time passed $16 \mathrm{~min}$, the wear morphology of both cutting tools began to clearly differ. Namely, the wear area of the cutting tool with a variable chamfered edge increased to $92215 \mu \mathrm{m}^{2}$ from $53469 \mu \mathrm{m}^{2}$, which is a growth of $72.5 \%$. At this point, the second crater wear zone occurred on the rake face, and its wear area was clearly larger than that of the cutting tool with an invariable chamfered edge, which resulted from the extension of the tool-chip contact area under the effect of the chip removal mechanism of the spiral cutting edge on the cutting tool with a variable chamfered edge. By further observing the wavy chip morphology formed during the cutting process, it

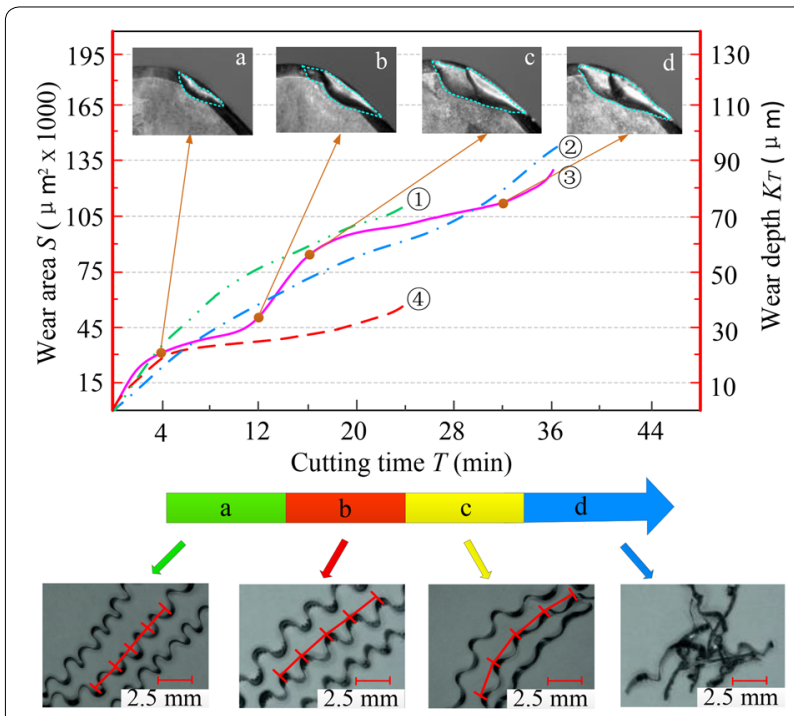

(1) - Wear depth of cutting tool with invariable chamfered edge (2) - Wear depth of cutting tool with variable chamfered edge (3) - Wear area of cutting tool with variable chamfered edge (4) - Wear area of cutting tool with invariable chamfered edge

Figure 5 Rake wear change curves of the two cutting tools with different chamfered edges 
can be clearly found that, as the cutting proceeded, the contact length between the chips and rake face (namely, the distance between two peaks of the chips) increased gradually and bent, and as the contact area extended beyond the second crater zone in particular, the chips gradually broke.

Figure 6 shows the extension of the crater wear cross-section $\mathrm{H}$ of the two tools with different chamfered edges as the cutting time continued. It can be seen from Figure 6 that the crater wear began with the chamfered surface close to cutting edge, but as the cutting proceeded, the crater wear area extended gradually toward the two directions of the rake face and cutting edge, and the crater depth gradually increased. When the cutting time passed 16 min, the crater wear border of the tool with a variable chamfered edge extended toward the cutting edge by $34 \mu \mathrm{m}$ and toward the rake face by $115 \mu \mathrm{m}$, whereas that of the tool with an invariable chamfered edge extended toward the cutting edge by $70 \mu \mathrm{m}$ and toward the rake face by $72 \mu \mathrm{m}$. At this moment, the crater wear area of the tool with a variable chamfered edge was already beyond the chamfered surface and extended toward the rake face, whereas that of the tool with an invariable chamfered edge was still concentrated at the chamfered surface. This proves that, for the tool with a variable chamfered edge, its wear area extended more slowly toward the cutting edge; in addition, the distance from the crater wear bottom to the cutting edge $L$ was clearly larger than that of the tool with an invariable chamfered edge. Therefore, in comparison, the tool with a variable chamfered edge

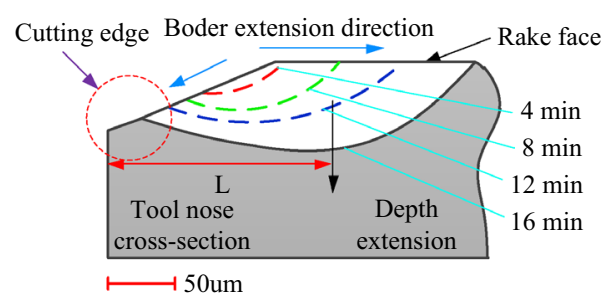

a Cutting tool with variable chamfered edge

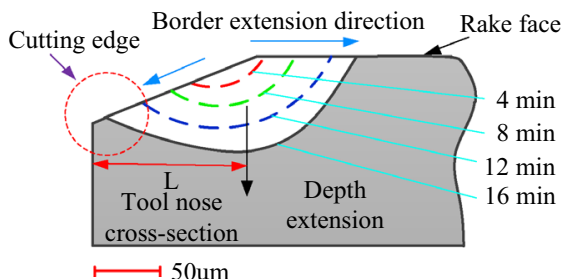

b Cutting tool with invariable chamfered edge

Figure 6 Extension of crater wear cross-section $\mathrm{H}$ of the two different tools has an ideal retentivity of the cutting edge, which helps prolong the tool life.

Figure 7 shows the change curves of the maximum flank wear width $V B_{\max }$ and flank wear length $b$ of the two tools with different chamfered edges as the cutting time continued. It can be seen from Figure 7 that, as the cutting proceeded, the flank wear length $b$ of the tool with a variable chamfered edge varied less and was approximately 1.2-times as long as that of the tool with an invariable chamfered edge. When the cutting time passed $12 \mathrm{~min}$, the flank wear $V B_{\max }$ of the tool with a variable chamfered edge reached $52 \mu \mathrm{m}$, which is obviously smaller than that of the tool with an invariable chamfered edge, that is, approximately one half. Moreover, the second crater wear area of the tool with a variable chamfered edge exerted a smaller impact on the flank wear $V B_{\max }$; in addition, it grew approximately linearly, but clearly more slowly than that of the tool with an invariable chamfered edge. When the cutting time reached $32 \mathrm{~min}$, the cutting edge of the tool with a variable chamfered edge showed an obvious chipping, and meanwhile the corresponding workpiece surface morphology was clearly deteriorated, whereas that of the tool with invariable chamfered edge was already broken when cutting for $24 \mathrm{~min}$.

\subsection{Analysis of Tool Wear Mechanism}

Figure 8(a) and (b) show the wear morphology of the tool with a variable chamfered edge when the flank wear was $52 \mu \mathrm{m}$, whereas Figure 8(c) and (d) show the wear morphology of the tool with an invariable chamfered edge when the flank wear was $55 \mu \mathrm{m}$. For an analysis of the wear mechanism of the tool with a variable chamfered edge, a scanning electron microscope with an inbuilt EDS was used to analyze the changes in energy spectrum

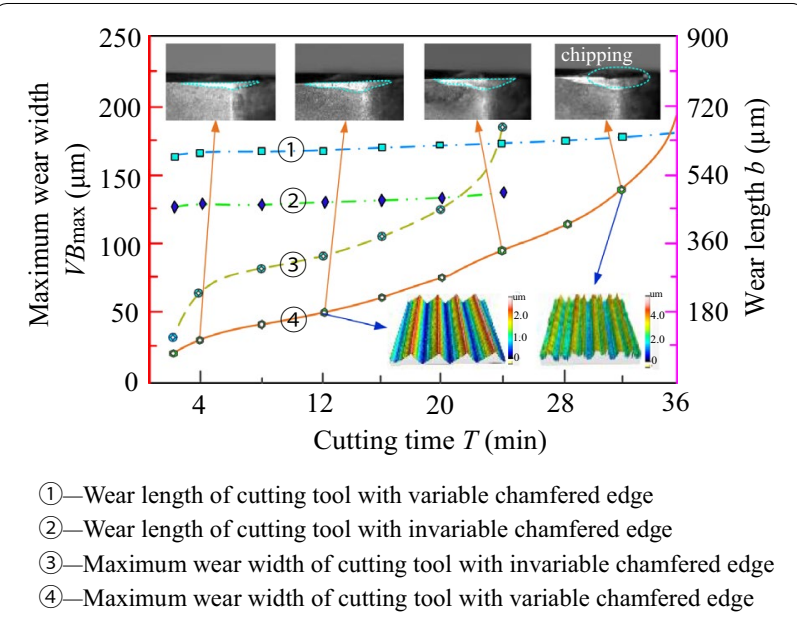

Figure 7 Change curves of flank wear of two tools with different chamfered edges 


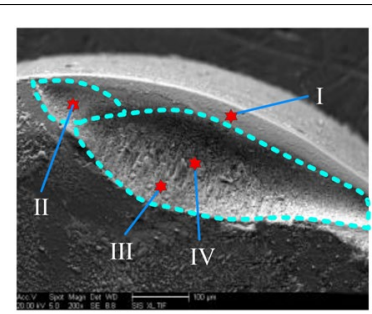

a Rake face of the tool with variable chamfered edge

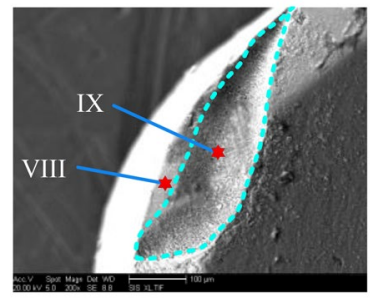

c Rake face of the tool with invariable chamfered edge

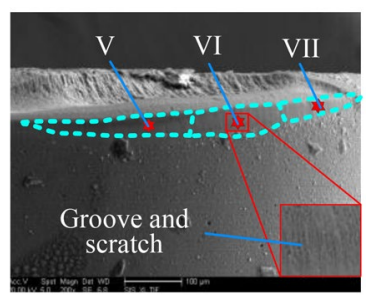

b Flank face of the tool with variable chamfered edge

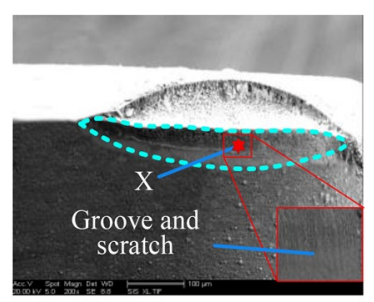

d Flank face of the tool with invariable chamfered edge

Figure 8 SEM morphology of two tools with different chamfered edges

of all elements to find the reasons for the tool wear. Thus, four test points were chosen in different wear areas of the rake face, namely, point I at the brim of the cutting edge, points II and IV at the crater bottom, and point III at the border of the crater wear area, as shown in Figure 8(a). In the same way, three test points were chosen in different wear areas of the flank face, that is, VI in the middle, and V and VII at both ends, as shown in Figure 8(b). In addition, in the corresponding rake and flank wear areas of the tool with an invariable chamfered edge, three test points were also chosen, namely, VIII, IX, and X, as shown in Figure 8(c) and (d).

\subsubsection{Analysis of Rake Wear Mechanism}

Figure 9 shows the element composition of all test points on the rake face of the tool with a variable chamfered edge. It can be seen that the elements $\mathrm{Fe}, \mathrm{O}$, and $\mathrm{C}$ were added in the crater wear, of which the elements Fe and $\mathrm{C}$ were from the workpiece, whereas element $\mathrm{O}$ was from the outer environment. Considering the existence of the elements above, it can be judged initially that the oxidation wear and diffusion wear both occurred in the wear area. Through a further comparison of the element content of all points I, II, III, and IV, it can be seen that the content of $\mathrm{Fe}$ and $\mathrm{O}$ at point II of the crater wear bottom was the highest, and was clearly higher than that at point IV, which indicates the above-mentioned formation sequence of the two wear areas. Meanwhile, the $\mathrm{O}$ content was apparently higher than the Fe content, which indicates that $\mathrm{O}$ reacted with $\mathrm{Fe}$, forming the

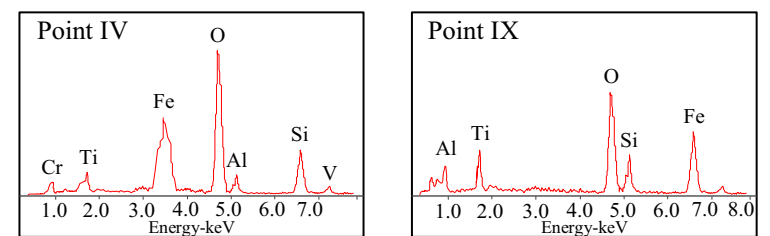

a Element analysis of two tools with different chamfered edges

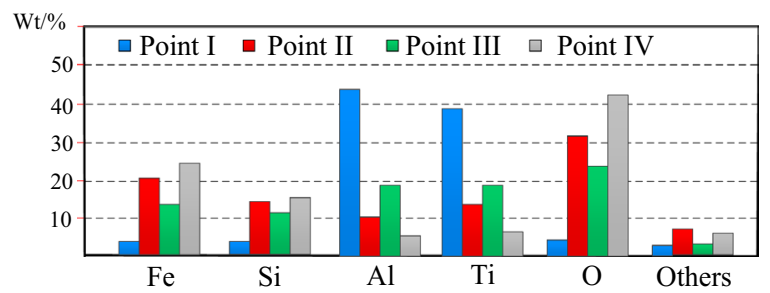

b Element analysis in the rank wear area of the tool with variable chamfered edge

Figure 9 Element analysis of the rake wear area

corresponding oxides, or even reacted in a complicated manner with the other elements. Compared with point VIII, the contents of $\mathrm{Al}$ and $\mathrm{Ti}$ at point I were higher, whereas those of $\mathrm{Fe}$ and $\mathrm{Si}$ were lower and approximated the tool matrix element content, which showed that the cutting edge wear of the tool with a variable chamfered edge was minor and that the cutting edge was well protected. Compared with point IX of the tool with an invariable chamfered edge, the higher $\mathrm{O}$ content of point IV at the crater wear bottom of the tool with a variable chamfered edge indicated that the oxidation and diffusion wear mechanism in the rake wear of the tool with a variable chamfered edge had clearly a higher proportion than the tool with an invariable chamfered edge.

\subsubsection{Analysis of Flank Wear Mechanism}

It can be easily seen from Figure 8(b) that a large number of long groove-shaped dents occurred on the flank wear face because hard spots in the machined surface material exerted scraping and a grinding impact on the flank face, which wore the binder down, and as a result, CBN granules peeled off easily and formed grooves. Here, the abrasive wear occurred similarly to the wear mechanism of the tool with an invariable chamfered edge. Through the energy spectrum analysis of points V, VI, and VII, it was found that only a few Fe, O, and $\mathrm{Si}$ elements existed at the above three points, whereas more $\mathrm{Al}$ and $\mathrm{Ti}$ elements were shown from the binder. Nonetheless, no obvious oxidation and diffusion wear occurred, and here the abrasive wear was still the main factor. The contents of all elements at point VI were further tracked, and the variation with the maximum 

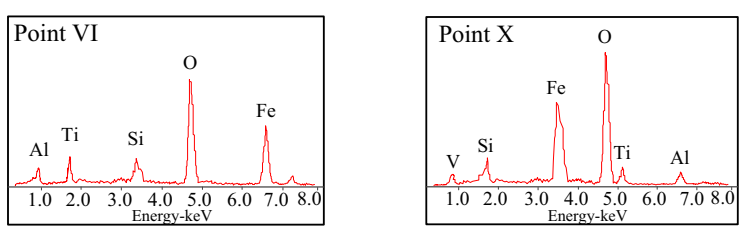

a Element analysis of two tools with different chamfered edges

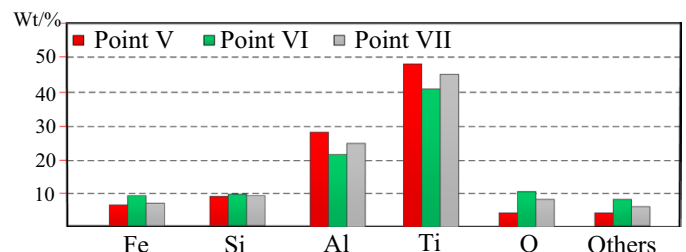

b Element analysis in the flank wear area of the tool with variable chamfered edge

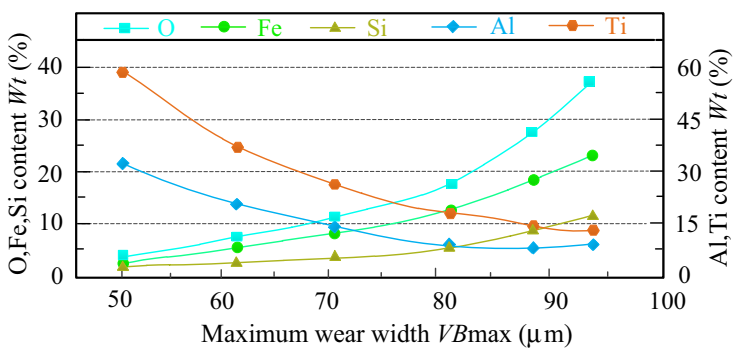

c Elements analysis in the flank wear area of the tool with variable chamfered edge under different wear conditions

Figure 10 Element analysis of the flank wear area

wear width $V B_{\max }$ was analyzed, as shown in Figure 10. With an increase in $V B_{\max }$, the contents of Fe, $\mathrm{O}$, and $\mathrm{Si}$ increased, whereas those of $\mathrm{Al}$ and $\mathrm{Ti}$ decreased, which indicated that the proportion of oxidation and diffusion wear increased. By comparing the contents of the elements at test points $\mathrm{VI}$ and $\mathrm{X}$, when $V B_{\max }$ was $0.05 \mathrm{~mm}$, it was shown that the flank oxidation and diffusion wear of the tool with a variable chamfered edge had a smaller proportion than the tool with an invariable chamfered edge. By comparing the contents of the elements at test points V, VI, and VII in the flank wear area of the tool with a variable chamfered edge, it was found that the contents of $\mathrm{O}, \mathrm{Fe}$, and $\mathrm{Si}$ at point VI were evidently higher than those at points V and VII, which showed that the oxidation and diffusion wear at the middle point VI were more serious than those at both end areas. This is because, during the cutting process, the cutting load concentration and poor thermolysis in area $M$ resulted in an accumulation of the cutting temperature. Consequently, the oxidation and diffusion wear were aggravated, and the cutting-edge strength decreased, which also partly explain why the wear proportion of area $\mathrm{M}$ was higher than that of areas $\mathrm{J}$ and $\mathrm{N}$.

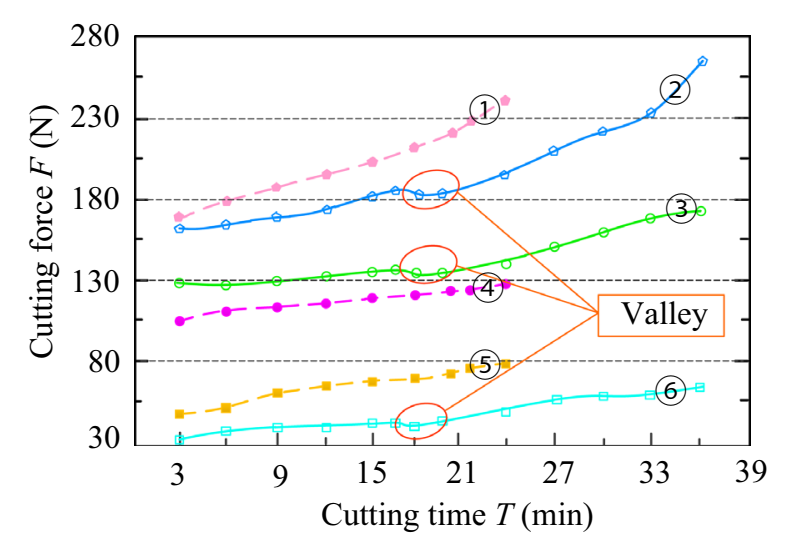

(1)-Radial force $F_{\mathrm{y}}$ of the tool with invariable chamfered edge

(2)-Radial force $F_{\mathrm{y}}$ of the tool with variable chamfered edge

(3) - Tangential force $F_{\mathrm{z}}$ of the tool with variable chamfered edge

(4)-Tangential force $F_{\mathrm{z}}$ of the tool with invariable chamfered edge

(5)-Axial force $F_{\mathrm{x}}$ of the tool with invariable chamfered edge

(6) - Axial force $F_{\mathrm{x}}$ of the tool with variable chamfered edge

Figure 11 Varying curves of cutting forces of two tools with different chamfered edges

\subsection{Analysis of the Effect of Tool Wear on Cutting Force}

Figure 11 shows the varying curves of the cutting forces of the two tools with different chamfered edges during the wear process. It can be seen from Figure 11 that, with the aggravation of the tool wear, all cutting forces of the two cutting tools varied almost identically, i.e., all cutting forces gradually increased, namely, the radial force $F_{\mathrm{y}}$ clearly varied, whereas the axial force $F_{\mathrm{x}}$ and tangential force $F_{\mathrm{z}}$ slightly increased. In addition, $F_{\mathrm{y}}$ and $F_{\mathrm{x}}$ of the tool with a variable chamfered edge were both minor to those of the tool with an invariable chamfered edge because the flank wear of the former was slighter than that of the latter, while $F_{\mathrm{z}}$ was bigger for the tool with a variable chamfered edge than that of the tool with an invariable chamfered edge because the spiral edge line of the tool with a variable chamfered edge increased the contact area between the tool and workpiece, and when moving along the feed direction the tool bore increased the cutting load. As the cutting proceeded, during the occurrence of the second crater wear, all cutting forces of the tool with a variable chamfered edge decreased, and here obvious troughs appeared, which is attributed to the fact that the formation of the second crater wear area increased the chip-breaking area, and thus the chips were more easily removed. As a result, all cutting forces decreased. 


\section{Conclusions}

Based on a comparative cutting experiment of two PCBN tools, one with a variable chamfered edge and the other with an invariable chamfered edge, a study on the tool wear morphology and wear mechanism was carried out, and the effect of the tool wear on the cutting forces was analyzed. Thus, the following conclusions were drawn.

1. The variable chamfered structure improves the ability of the PCBN tool to remove the chips. A shallow large-area crater wear forms on the rake face and is far from the cutting edge, whereas a long triangular wear occurs on the flank face and is not a large or wide area.

2. The rake wear of the two cutting tools begins with a chamfered face at the cutting edge, and gradually extends toward both the rake face and cutting edge with an aggravation of the tool wear. In contrast to the cutter with an invariable chamfered edge, the cutter with a variable chamfered edge extends its rake wear slowly toward the cutting edge, but quickly toward the rake face, which demonstrates a better cutting edge maintenance.

3. The cutter with a variable chamfered edge clearly shows more oxidation and a greater diffusion wear mechanism on its rake face than the cutter with an invariable chamfered edge, which is particularly obvious in the first crater wear area. Its flank wear mechanism is mainly abrasive wear, and it becomes more complicated with an aggravation of the tool wear, including many wear mechanisms, such as oxidation wear, and diffusion wear.

4. The variable chamfered structure forms a helical cutting edge, which is helpful in partially decomposing the radial and axial cutting forces, and effectively improves the stressed conditions of the cutting edge. Even under a state of serious wear, all cutting forces increase more slowly than a cutter with an invariable chamfered edge, and thus a cutter with a variable chamfered edge possesses a better cutting performance.

\section{Authors' Contributions}

TC was in charge of the whole trial; TC and LS wrote the manuscript; SL and XL assisted with sample preparation and experimental analysis. All authors read and approved the final manuscript.

\footnotetext{
Authors' Information

Tao Chen, born in 1979, is currently a professor at Harbin University of Science and Technology, China. He received his PhD degree from Harbin University of Science and Technology, China, in 2009. His research interests include highspeed hard machining and high-speed cutting tools.

Lixing Song, born in 1995, is a MS candidate at Harbin University of Science and Technology, China. He works on tool wear study.
}

Suyan Li, born in 1972, is a PhD candidate at Harbin University of Science and Technology, China. Her research interests include the design of cutting tool and its optimization.

Xianli Liu, born in 1961, is currently a professor and a PhD supervisor at Harbin University of Science and Technology, China. His main research interests include high efficiency cutting and cutting tool technology.

\section{Competing Interests}

The authors declare that they have no competing interests.

\section{Funding}

Supported by National Natural Science Foundation of China (Grant No. 51475125), and Heilongjiang Provincial Natural Science Foundation of China (Grant No. E2016047).

Received: 10 September 2018 Accepted: 8 April 2019

Published online: 23 April 2019

\section{References}

[1] S Chinchanikar, S K Choudhury. Machining of hardened steel: Experimental investigations, performance modeling and cooling techniques: A review. International Journal of Machine Tools and Manufacture, 2015, 89: 95-109.

[2] G Bartarya, S K Choudhury. State of the art in hard turning. International Journal of Machine Tools and Manufacture, 2012, 52: 1-14.

[3] C S Kumar, S K Patel. Application of surface modification techniques during hard turning: Present work and future prospects. International Journal of Refractory Metals and Hard Material, 2018, 76: 112-127.

[4] M Dogra, V S Sharma, A Sachdeva, et al. Tool wear, chip formation and workpiece surface issues in CBN hard turning: A review. International Journal of Precision Engineering and Manufacturing, 2010, 11(2): 341-358.

[5] S Saini, I S Ahuja, V S Sharma. Residual stresses, surface roughness, and tool wear in hard turning: A comprehensive review. Materials and Manufacturing Processes, 2012, 27(6): 583-598.

[6] O Gutnichenko, V Bushlya, J M Zhou, et al. tool wear and vibrations generated when turning high-chromium white cast iron with pcbn tools. Procedia CIRP, 2016, 46: 285-289.

[7] F Klocke, H Kratz. Advanced tool edge geometry for high precision hard turning. CIRP Annals-Manufacturing Technology, 2005, 54(1): 47-50.

[8] Y K Chou, C J Evans, M M Barash. Experimental investigation on CBN turning of hardened AISI 52100 steel. Journal of Materials Processing Technology, 2002, 124(3): 274-283.

[9] J M Zhou, H Walter, M Andersson, et al. Effect of chamfer angle on wear of PCBN cutting tool. International Journal of Machine Tools and Manufacture, 2003, 43(3): 301-305.

[10] R T Coelho, E G Ng, M A Elbestawi. Tool wear when turning hardened AISI 4340 with coated PCBN tools using finishing cutting conditions. International Journal of Machine Tools and Manufacture, 2007, 47(2): 263-272.

[11] J A Arsecularatne, L C Zhang, C Montross, et al. On machining of hardened AISI D2 steel with PCBN tools. Journal of Materials Processing Technology, 2006, 171(2): 244-252.

[12] G Poulachon, B P Bandyopadhyay, I S Jawahir, et al. The influence of the microstructure of hardened tool steel workpiece on the wear of PCBN cutting tools. International Journal of Machine Tools and Manufacture, 2003, 43(2): 139-144

[13] T Zhao, J M Zhou, V Bushlya, et al. Effect of cutting edge radius on surface roughness and tool wear in hard turning of AISI 52100 steel. International Journal of Advanced Manufacturing Technology, 2017, 91(9-12): 3611-3618.

[14] S R Das, D Dhupal, A Kumar. Study of surface roughness and flank wear in hard turning of AISI 4140 steel with coated ceramic inserts. Journal of Mechanical Science and Technology, 2015, 29(10): 4329-4340.

[15] N Anmark, T Bjork, A Ganea, et al. The effect of inclusion composition on tool wear in hard part turning using PCBN cutting tool. Wear, 2015 334-335: 13-22.

[16] K Ramanuj, A K Sahoo, P C Mishra, et al. An investigation to study the wear characteristics and comparative performance of cutting inserts 
during hard turning. International Journal of Machining and Machinability of Materials, 2018, 20(4): 320-344.

[17] F Mahfoudi, G List, A Molinari, et al. High speed turning for hard material with PCBN inserts: tool wear analysis. International Journal of Machining and Machinability of Materials, 2008, 3(1/2): 62-79.

[18] Y Huang, T G Dawson. Tool crater wear depth modeling in CBN hard turning. Wear, 2005, 258(9): 1455-1461.

[19] T Özel. Computational modelling of 3D turning: Influence of edge microgeometry on forces, stresses, friction and tool wear in PCBN tooling. Journal of Materials Processing Technology, 2009, 209(11): 5167-5177.

[20] T Özel, Y Karpat, A Srivastava. Hard turning with variable micro-geometry PCBN tools. CIRP Annals-Manufacturing Technology, 2008, 57(1): 73-76.

[21] J Angseryd, H O Andrén. An in-depth investigation of the cutting speed impact on the degraded microstructure of worn PCBN cutting tools. Wear, 2011, 271(9-10): 2610-2618.

[22] K Katuku, A Koursaris, I Sigalas. Wear mechanisms of PCBN cutting tools when dry turning ASTM Grade 2 austetmpered ductile iron under finishing conditions. Wear, 2010, 268(1): 294-301.

[23] E Uhlmann, H Riemer, D Schroter, et al. Investigation of wear resistance of coated PCBN turning tools for hard machining. International Journal of Refractory Metals and Hard Materials, 2018, 72: 270-275.
[24] L H Tang, Y J Sun, B D Li, et al. Wear performance and mechanisms of PCBN tool in dry hard turning of AISI D2 hardened steel. Tribology International, 2019, 132: 228-236.

[25] B Denkena, J Köhler, C Venturalnt. Grinding of PCBN cutting inserts. International Journal of Refractory Metals and Hard Materials, 2014, 42(1): 91-96.

[26] C Ventura, J Köhler, B Denkena. Strategies for grinding of chamfers in cutting inserts. Precision Engineering, 2014, 38: 749-758.

[27] T Chen, DY Wang, SY Li, et al. Manufacture and grinding accuracy detection of pcbn tools with variable chamfer edge. Journal of Mechanical Engineering, 2018, 54(11): 214-221. (in Chinese)

[28] B Denkena, J Köhler, B Breidenstein, et al. Influence of the cutting edge preparation method on characteristics and performance of PVD coated carbide inserts in hard turning. Surface and Coatings Technology, 2014, 254: 447-454.

[29] C Venture, J Kohler, B Denkena. Influence of cutting edge geometry on tool wear performance in interrupted hard turning. Journal of Manufacturing Processes, 2015, 19: 129-134.

[30] T Chen, J Guo, SY Li, et al. Experimental study on high-speed hard cutting by PCBN tools with variable chamfered edge. International Journal of Advanced Manufacturing Technology, 2018, 97(9): 4209-4216.

\section{Submit your manuscript to a SpringerOpen ${ }^{\circ}$ journal and benefit from:}

- Convenient online submission

- Rigorous peer review

- Open access: articles freely available online

- High visibility within the field

- Retaining the copyright to your article

Submit your next manuscript at $\boldsymbol{\nabla}$ springeropen.com 